\title{
Cobalt, chromium and molybdenum ions kinetics in the human body: data gained from a total hip replacement with massive third body wear of the head and neuropathy by cobalt intoxication
}

\author{
U. E. Pazzaglia $\cdot$ P. Apostoli $\cdot$ T. Congiu • \\ S. Catalani $\cdot$ M. Marchese $\cdot$ G. Zarattini
}

Received: 28 March 2010/Published online: 5 February 2011

(C) Springer-Verlag 2011

\begin{abstract}
Introduction A patient with a total hip replacement developed optic, acoustic and peripheral neuropathy from metal ions intoxication, due to the wear products released from the prosthesis. Subsequently the kinetics of the metal ions was studied.

Materials and methods Massive wear and acute intoxication allowed a study of the metal ions kinetics and of EDTA treatment.

Results Plasma and other organic fluids were saturated by each of the metal ions released from the exposed surface according to the solubility of each ion; a larger fraction of Co ions was bound within red cells, while the plasmatic fraction appeared more movable. In a patient with a prosthesis subjected to wear, the ions released are from the prosthetic and from the debris surface (spread in the body). The latter is a function of the number and size of particles. Discussion Revision of the prosthesis from the point of view of the metal ions kinetics corresponded to a reduction
\end{abstract}

Electronic supplementary material The online version of this article (doi:10.1007/s00402-011-1268-7) contains supplementary material, which is available to authorized users.

U. E. Pazzaglia · M. Marchese · G. Zarattini ( $\square)$

Orthopaedic Clinic, University of Brescia, Brescia, Italy

e-mail: gzarattini@yahoo.it; ortopedia2@ spedalicivili.brescia.it

P. Apostoli · S. Catalani

Department of Experimental and Applied Medicine,

Section of Industrial Hygiene, University of Brescia,

Brescia, Italy

e-mail: apostoli@med.unibs.it

T. Congiu

Department of Human Morphology,

University of Insubria, Varese, Italy

e-mail: terenzio.congiu@uninsubria.it of the releasing surface because of debris washed out by irrigation and tissue excision; however, the metal particles spread by lymphatic circulation continued to release ions even though the source of wear had been removed. Early diagnosis of high metal wear can be ascertained with mass spectrometry and after revision high levels of metal ions can only be reduced with repeated chelating treatment. It is preferable not to revise fractured ceramic components with a polyethylene-metal articulation.

Keywords Total hip replacement - Cobalt intoxication . Metal ions · Foreign body reaction $\cdot$ Prosthetic wear

\section{Introduction}

The increasing diffusion of metal-on-metal bearings in total hip replacement has renewed in recent years not only the interest for the local effects of metal particles, but also for the potential damages of ions released by the surface of the prosthesis or by the products of wear [1-4]. In general, the documented levels of metal ions in blood, plasma or urine of different types of implant [5-13] or correlated conditions like loosening $[14,15]$ are not comparable with those observed in professionally exposed workers, due to the way of absorption (usually inhalation) and also the excretion rate is very different [16-18]. However, in both situations the risks connected with intoxication have been considered so far as potential. Intoxication by wear products of a hip prosthesis has been to the best of our knowledge rarely observed [19-21].

The kinetics of metal ions in THR population, even if already studied [3, 5, 7, 9-15, 19-24], remain a complicated topic because of the difficulty in determining the release rate and the active surface which includes both the 
metallic components of the prosthesis and the wear particles that are disseminated widely in the body through the lymphatics [22-24].

A severe metal ion intoxication [20] allowed a detailed study of the parameters of wear and the kinetics of metal ions released in the human body by a THR. It nevertheless was an interesting case to apply and analyse the effects of the therapy with chelating agent (EDTA), which is already been studied and currently used only in occupational metal intoxications $[16-18,25]$ but never before in a THR.

\section{Materials and methods}

\section{Clinical background}

A 58-year-old female patient had a THR with a titanium cementless stem and a ceramic-ceramic coupling, when she felt sudden pain in her hip and the head was found to be broken. A polyethylene liner coupled with $\mathrm{Co}-\mathrm{Cr}$ head were inserted in the place of the ceramic components, while the stem and the cup were left in place. Five months later the patient started to complain of reduction of sight and hearing whose aetiology remained unknown. Two months later her conditions worsened resulting in an almost complete loss of sight, hearing, combined with weakness of the upper and lower limbs, paresthesia, diffused anaesthesia constraining the patient to a wheelchair. The aetiology of neuropathy was revealed 1 year later when metal ions levels were measured in biological fluids [19].

The complete clinical records including X-rays and CT imaging, the components of the removed hip prosthesis, the tissue histology and the periprosthetic fluid samples collected at revision were available for the study.

\section{Wear particles analysis}

The analysis of the wear particles was carried out on the samples of interstitial fluid drained during revision. They were diluted in distilled water (1:2), centrifuged at 2,500 rpm for $5 \mathrm{~min}$ and the deposit was suspended again in a solution of hydrochloric acid (8\%) then centrifuged at 2,500 rpm for $5 \mathrm{~min}$. The procedure was repeated twice with distilled water to remove the acid. The final deposit was put on glass and polystyrene slides which were processed for SEM and EDX analysis. The slides were fixed on stubs with conducting tape, coated with a thin layer of gold in a vacuum sputter Emitech K550 (Emitech United, Ashford, Kent, UK) and studied with a FEG XL30 scanning electron microscope (Philips, Eindhoven, Netherlands) in the direct and backscattered mode. A quantitative EDX analysis was performed with an EDAX (Edax Inc., Mahwah, New Jersey, USA) device equipped with Genesis 2000 software.
Metal ions determination

Blood samples were obtained using a disposable intravenous cannula; the first $10 \mathrm{ml}$ were discarded and further $10 \mathrm{ml}$ of blood were withdrawn and transferred into separate $2 \mathrm{ml}$ tubes containing lithium-heparin anticoagulant. The blood then was centrifuged at $3,000 \mathrm{rpm}$ for $10 \mathrm{~min}$ and the plasma was frozen and stored at $-80^{\circ} \mathrm{C}$ until the analysis was performed.

To collect a sample of urine the patient was catheterized and a sample for analysis was drawn from the sac considering the total volume. Cephal-rachidean fluid was obtained by rachiocentesis at lower lumbar level.

ICP-MS (ELAN DRC II, Perkin Elmer, Waltham, USA) equipped with dynamic cell reaction (DRC) was used for determinations.

The samples of plasma and blood were diluted with Triton $0.05 \%$. Urine and cephal-rachidean fluid samples were bi-distilled with water, for inorganic trace analysis (Merck KgaA) [26]. Traces of titanium in the urine sample was determined by a direct atomic absorption method, a spectroscopy AAS graphite tube atomizer furnace (Varian Duo, GTA 120, AA 240 Z).

The calibration standards were prepared by standard solutions of single elements ranging from 0.5 to $1,000 \mu \mathrm{g} / \mathrm{l}$ : cobalt in $\mathrm{HNO}_{3} 2 \%$ mono elemental standard solution (Carlo Erba Reagenti, Milano, Italy); vanadium in $\mathrm{HNO}_{3}$ 5\% mono elemental standard solution (Carlo Erba Reagenti, Milano, Italy); chromium in $\mathrm{HCl}$ atomic absorption standard solution (Sigma-Aldrich, Milwaukee, USA); molybdenum and titanium in $\mathrm{H}_{2} \mathrm{O}$ atomic absorption standard solution (Sigma-Aldrich, Milwaukee, USA).

The limit of detection (LOD), calculated as three standard deviations of the background signal obtained on ten blind samples were Cr: $0.05 \mu \mathrm{g} / \mathrm{l}$ (U, P, B); Co: $0.05 \mu \mathrm{g} / \mathrm{l}$ (U, P), $0.1 \mu \mathrm{g} / \mathrm{l}$ (B); Mo: $0.05 \mu \mathrm{g} / \mathrm{l}$ (U), $0.1 \mu \mathrm{g} / \mathrm{l}$ (P, B); V: $0.05 \mu \mathrm{g} / \mathrm{l}(\mathrm{U}, \mathrm{P}, \mathrm{B})$.

\section{Results}

Massive third body wear of a THR Co-Cr-Mo head (Fig. 1a) was produced after removal of a broken ceramic head by the particles of the same material which remained embedded on the surface of the polyethylene socket used in revision (Fig. 1c). There were no local troubles in the hip, however, from the X-rays and the CT performed, radiopaque longitudinal deposits along the diaphysis of the femur and in the posterior iliac fossa were observed and initially interpreted as ossifications (Fig. 2a-b).

The clinical disease with optic, acoustic and peripheral neuropathy had been previously reported [20] and the 

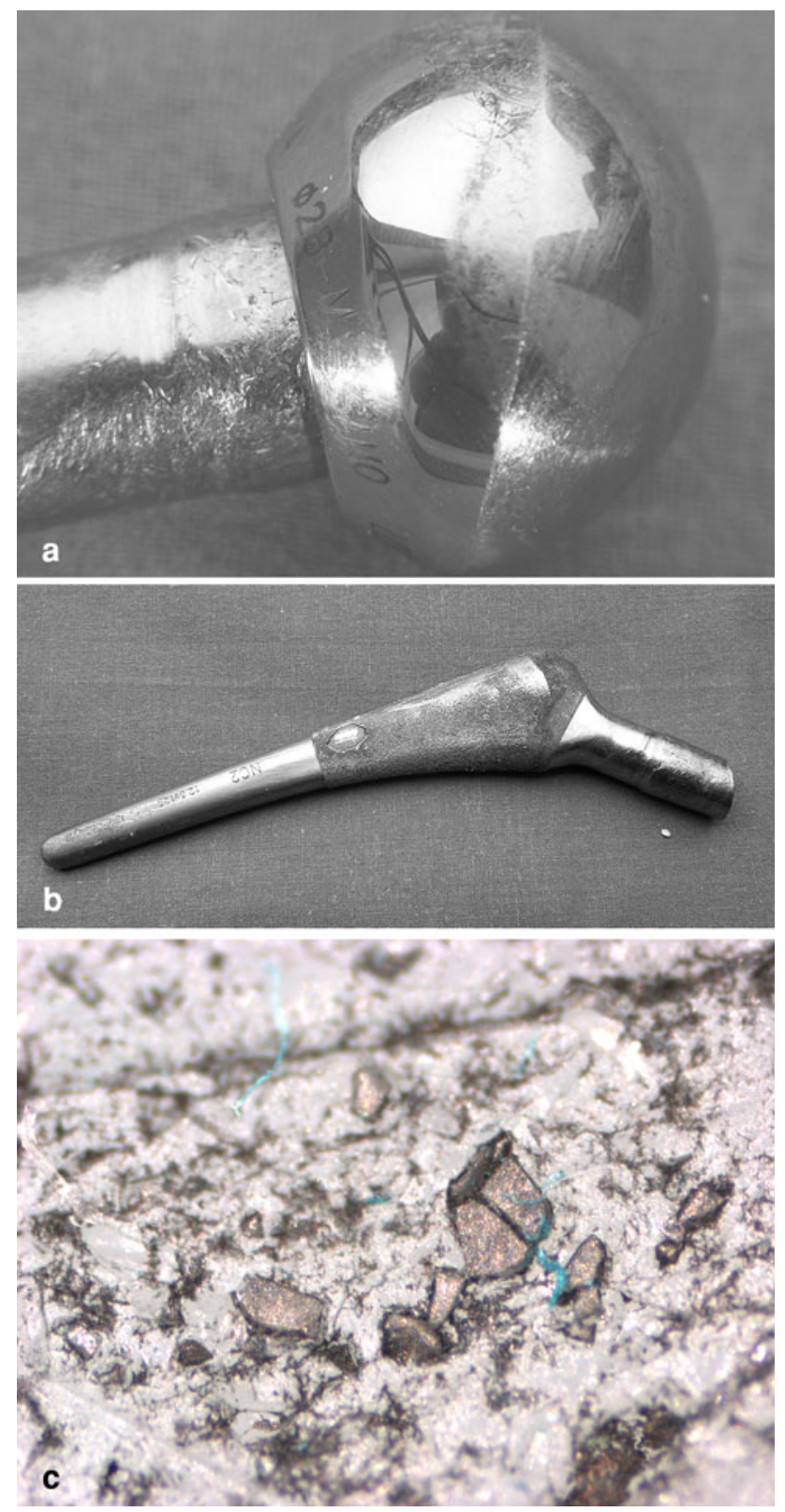

Fig. 1 a Massive polar wear of the Co-Cr-Mo head was observed; surface damage and loss of material from the neck and Morse cone was also present (2nd revision). b The Morse cone was deformed and scraped (fretting) with loss of metal from the tip; signs of fretting and loss of the porous coating on the lateral surface were evident (2nd revision). c Ceramic particles set in the polyethylene liner causing third body wear with the Co-Cr-Mo alloy head (2nd revision); $25 \times$

temporal sequence of the wear history and metal ions release is presented in Fig. 3.

The prosthetic head had lost about $1 / 3$ of its volume (Fig. 1a); the neck and the stem were also damaged, with loss of material and superficial fretting (Fig. 1b). The weight loss of the components (calculated by the difference between the manufacturer specifications and the worn
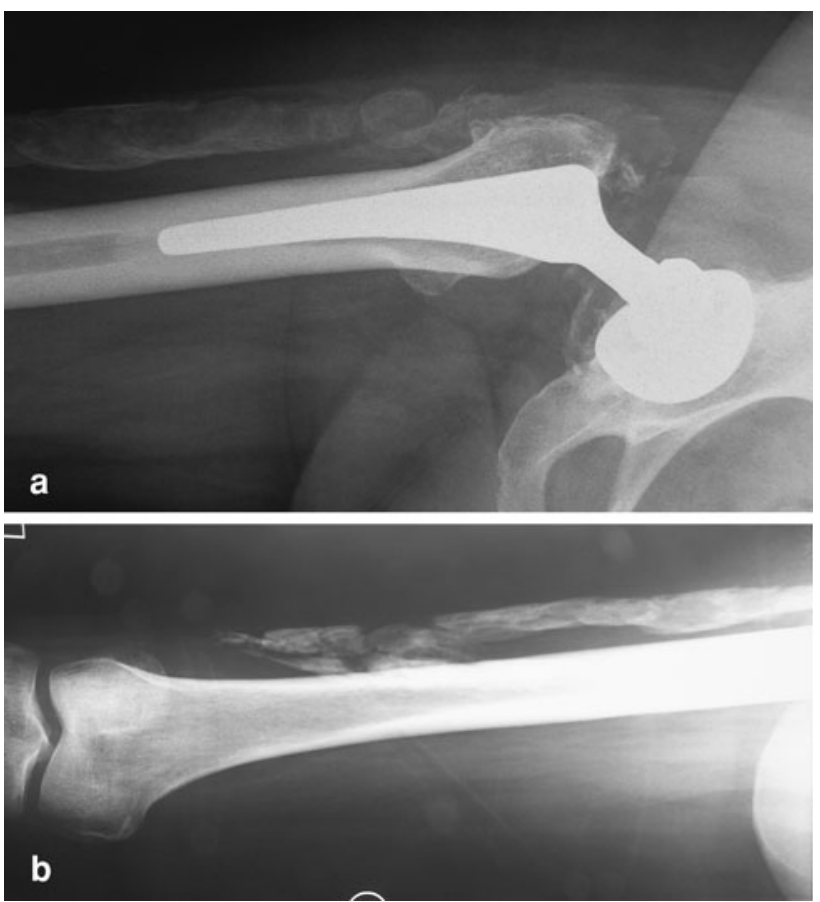

Fig. 2 a, b X-rays taken 14 months after the first revision when a Co-Cr-Mo alloy head and a polyethylene liner were inserted on the original titanium stem and cup in substitution of the broken ceramic head and ceramic liner. The radiopaque deposits extending distally between the vastus lateralis and the fascia lata were at first interpreted as ossifications, but resulted to be accumulation of metallic debris

components) was $15 \mathrm{~g}$ for the Co-Cr-Mo head and $0.72 \mathrm{~g}$ for the titanium stem.

Two wear modes were documented by the surface analysis of the removed prosthetic components: third body wear of the Co-Cr-Mo head (Fig. 1a) and fretting of the neck and of the stem porous coating (Fig. 1b).

Metal particles had spread along the intermuscular septa, forming a bursa whose surface was heavily stained by the black deposits. There was no fibrous capsule around the prosthetic joint and this space was in continuity with the bursae extending both distally and proximally.

Particles phagocytosis by macrophages in the periprosthetic tissue was scanty (Fig. 4); in contrast, metal particles were collected in a suspension of the interstitial fluid which diffused far from the joint between the muscles in absence of a fibrous capsule around the prosthetic joint (Fig. 2a).

SEM observation coupled with EDX analysis allowed to distinguish in the smears of the interstitial fluid the $\mathrm{Co}-\mathrm{Cr}-$ Mo particles from those of titanium (Fig. 5a-c). The latter were few, heterogeneously distributed and could only be identified in few fields. Ceramic particles were occasionally observed in histological sections (Fig. 4), but not in the interstitial fluid smears. 
Fig. 3 Timetable of Ti and $\mathrm{Co}-\mathrm{Cr}-\mathrm{Mo}$ alloy particles production and end-points of the implant history. The titanium hip prosthesis with a ceramicceramic coupling has been implanted 5 years before time $t_{0}$. The patient could walk without local complaints until time $t_{2}$, when neuropathy developed

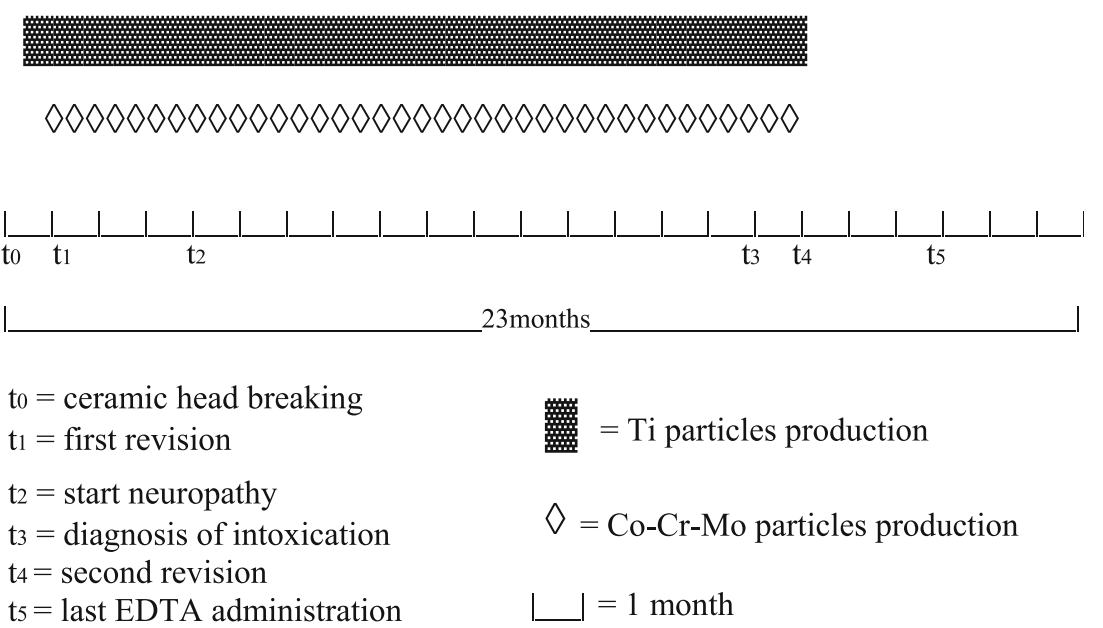

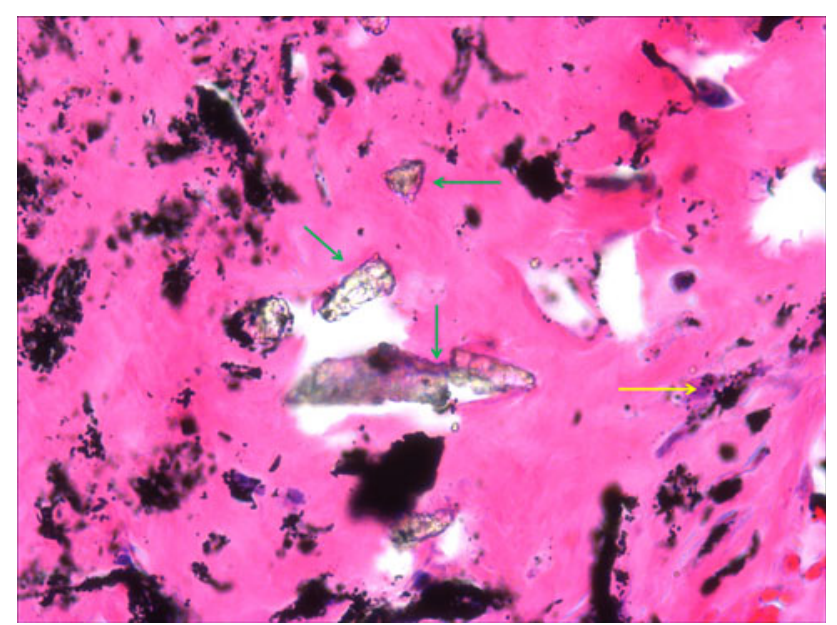

Fig. 4 Haematoxylin-eosin (2nd revision, 200×). Metallic debris particles in the periprosthetic tissue: few of them have been phagocytosed by macrophages (yellow arrow) while most of them are free or form clusters within the fibrin clot. Ceramic particles left by the 1 st revision are also evident (green arrows)

From the time of the diagnosis to the removal of the prosthesis (70 days) therapy with a chelating agent (EDTA) was performed at regular intervals of about 7 days. Both $\mathrm{Co}$ and $\mathrm{Cr}$ in plasma after an initial decrement following the two first EDTA administrations increased again, even if at levels lower than before. Mo levels were relatively low in respect to $\mathrm{Co}$ and $\mathrm{Cr}$, without any correlation with the proportion of the three elements in the alloy (ISO 5832/12: Co 59.5-65.5\%, Cr 26-30\%; Mo 5-7\%). From the third EDTA administration onward there was a short fall of the soluble ions level in plasma which lasted for about 3 days and gave a swinging profile to the graph (Table 1). During the 2 months of therapy the decrement of Co levels were more evident in blood than in plasma; in the latter, the mean level of Co ions was about a half of that in blood. Urine levels showed a peak after each EDTA administration (Table 2).
Cr levels in plasma and blood after the initial decrement maintained a constant concentration throughout the whole period, with higher values in plasma than in blood. The $\mathrm{Cr}$ urinary excretion pattern did not differ from that of $\mathrm{Co}$, but the absolute values of metal ions eliminated were higher in the latter (Table 3). The Mo ion levels were in the range of $2-4 \mu \mathrm{g} / \mathrm{l}$ with no significant differences between plasma and blood. The removal of the prosthesis produced a decrement of about half of Co in plasma and blood, while in $\mathrm{Cr}$ reduction was less evident (Tables 2,3 ).

Cephal-rachidean fluid was assessed twice at days 8 , and 108 with the following concentrations: Co 11.4-2.6 $\mu \mathrm{g} / \mathrm{l}$; Cr 4.4-0.8 $\mu \mathrm{g} / \mathrm{l} ;$ Mo $18-0.5 \mu \mathrm{g} / \mathrm{l}$.

Due to interference and sensibility $\mathrm{Ti}$ ion levels were assessed only in urine before and ten times after the removal of the prosthesis. The concentrations of these ions were $21 \mu \mathrm{g} / \mathrm{l}$ before the operation and decreased to $9-10 \mu \mathrm{g} / \mathrm{l}$ in the repeated dosages after the surgery. The pre-operative values were comparable with the reference values in patients with titanium alloy prosthesis with a regular wear rate [8] and the post-operative values were similar to normal population [25].

\section{Discussion}

A combination of factors such as the inappropriate revision of the broken ceramic head, which caused the third body wear and the massive and fast production of $\mathrm{Co}-\mathrm{Cr}-\mathrm{Mo}$ particles, but also, the delayed diagnosis of the neuropathy aetiology and the medical treatment with a chelating agent offered the chance to study the kinetics of metal ions released by a joint prosthesis with a high wear rate. Chelating therapy is currently used in occupational metal intoxications, but never before in a THR.

It has been well documented that loosened hip prostheses have higher serum levels of metals than successful 

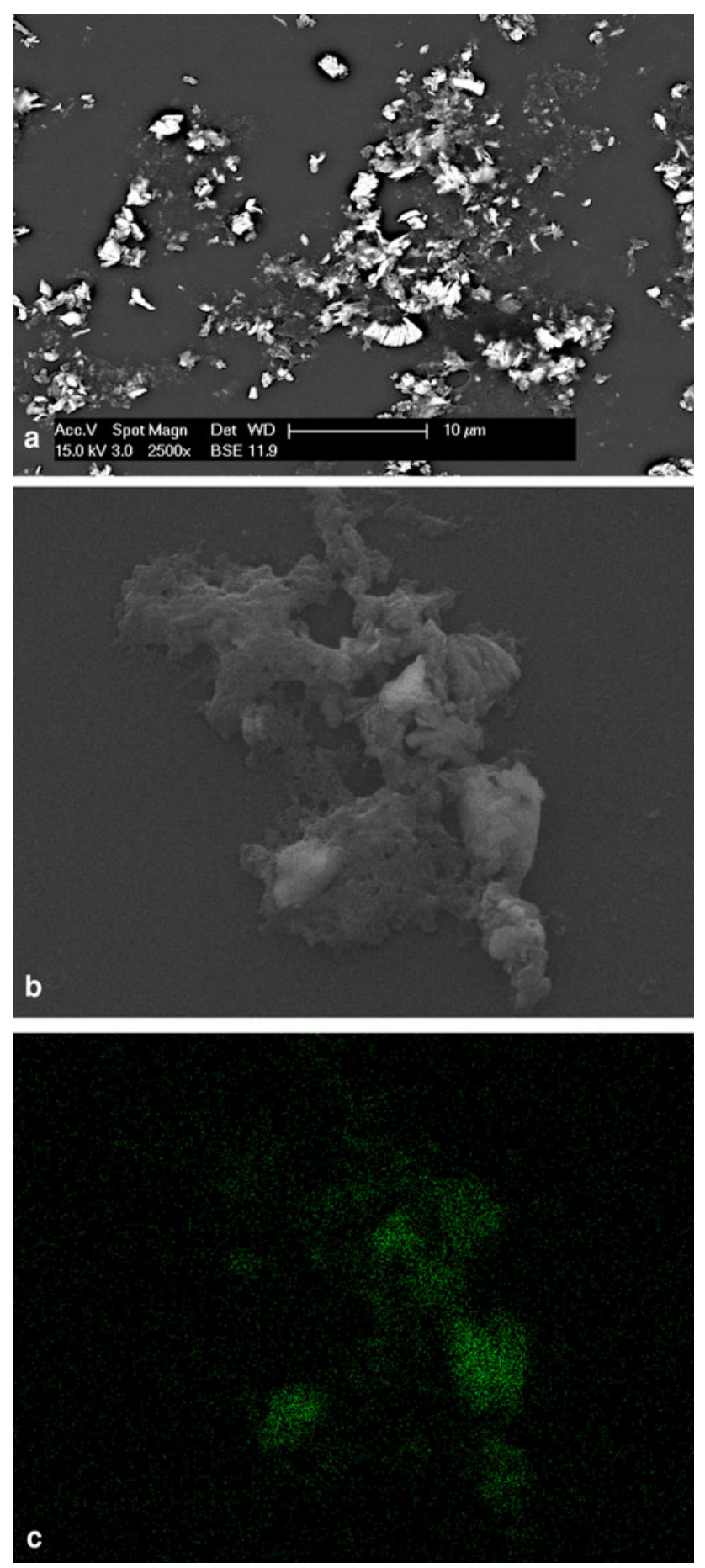

Fig. 5 a SEM low power view $(2,500 \times)$. Metal debris present in the interstitial fluids drained during the second revision: since the particles were embedded in a fibrin clot repeated lavages in a weak acid solution were necessary before smearing the fluid on a polystyrene slide. b SEM $(20,000 \times)$. Particles partially embedded in organic material not completely digested by hydrochloric acid solution. c Energy dispersive X-rays analysis of the same field of $5 \mathrm{~b}$ documented they are $\mathrm{Co}-\mathrm{Cr}-\mathrm{Mo}$ alloy particles (green for $\mathrm{Co}$ emission) and stable prostheses [14, 15] as well as metal-on-metal prostheses have higher serum values of metals than metalon-polyethylene couplings $[6,11]$ and also the head diameter of metal-on-metal prostheses showed a direct correlation with the level of soluble metals [13].

Since the release occurs from the surface of the implanted material [27], the surface available for release from a prosthesis is limited to about $20 \mathrm{~cm}^{2}$, but it increases remarkably when wear particles are produced.

Metal particles can be easily identified in stained tissue sections or on smears of the periprosthetic fluid as irregular, black bodies [28, 29]; however, morphological size assessment with light microscopy is questionable as it is not possible to distinguish individual particles from clusters. SEM examination of the particles suspension as carried out in this study was the only reliable method of measurement.

The surface increments of the alloy volume lost by the prosthetic components with respect to the bulk materials can explain the very high release of soluble ions in blood, plasma and urine. A further factor was the high rate of particles production, which favoured diffusion of the particles-loaded interstitial fluid, rather than the collection around the prosthetic joint of a granulation tissue formed by macrophage. This aspect was well documented in $\mathrm{X}$-rays by the presence of radiopaque deposits mimicking an ossifying myositis [30]. Also in the case reported by Steens et al. [21] with similar symptoms of neuropathy and in that of Oldenburg et al. [19], an unusually high quantity of metallic debris was evident around the articulating space of the prosthesis, which indicated a high wear rate of these metal-on-metal bearings but with the products of wear contained by a capsule around the prosthetic joint. A massive metallosis by third body wear of ceramic particles embedded in the bearing surface of a polyethylene cup was also reported by Kempf and Semlitsch [31], but the metal ions released by the stainless steel debris did not provide evidence of intoxication. Other examples of third body wear have been reported with fragments of porous metal surface [32].

The toxicokinetics of metal ions from joint replacements is completely different from that of the inhalation exposure of these metal ions, as well as of the other exposures such dermatological or oral route, which are common to professionally exposed workers or to the general population $[25,33]$, because in the former the ions source is inside the body.

The treatment with EDTA in this case caused a shortterm lowering of the levels of $\mathrm{Co}, \mathrm{Cr}$ and $\mathrm{Mo}$ in plasma and a corresponding peak of the urinary excretion; however, after approximately 3 days they increased again. This trend 
Table 1 Blood levels of cobalt, chromium and molybdenum ions from the diagnosis to the end of therapy with EDTA

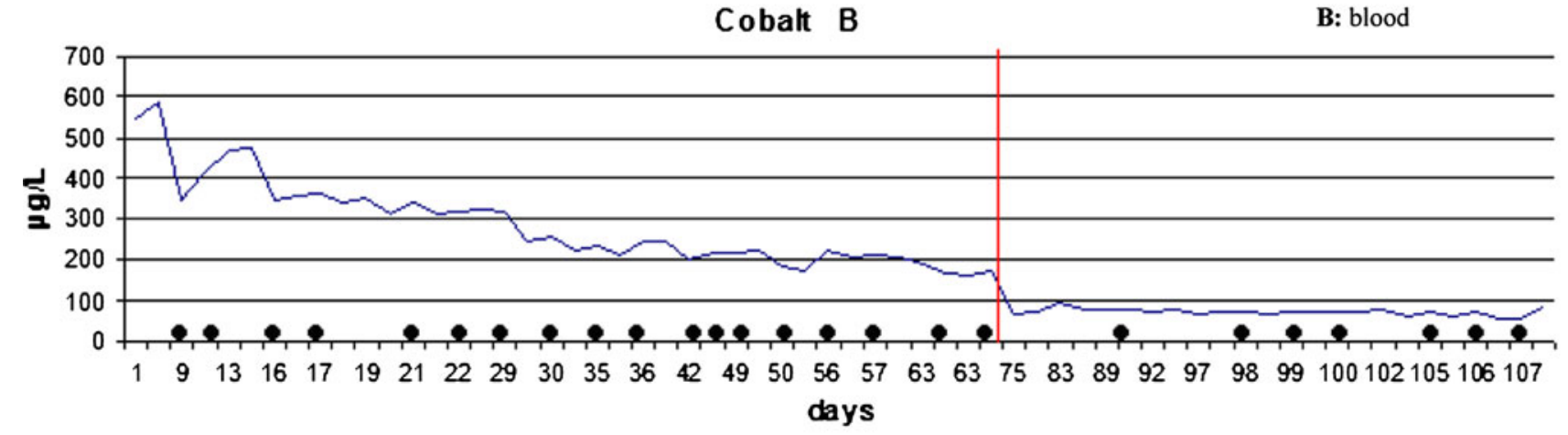

\section{ChromiumB}

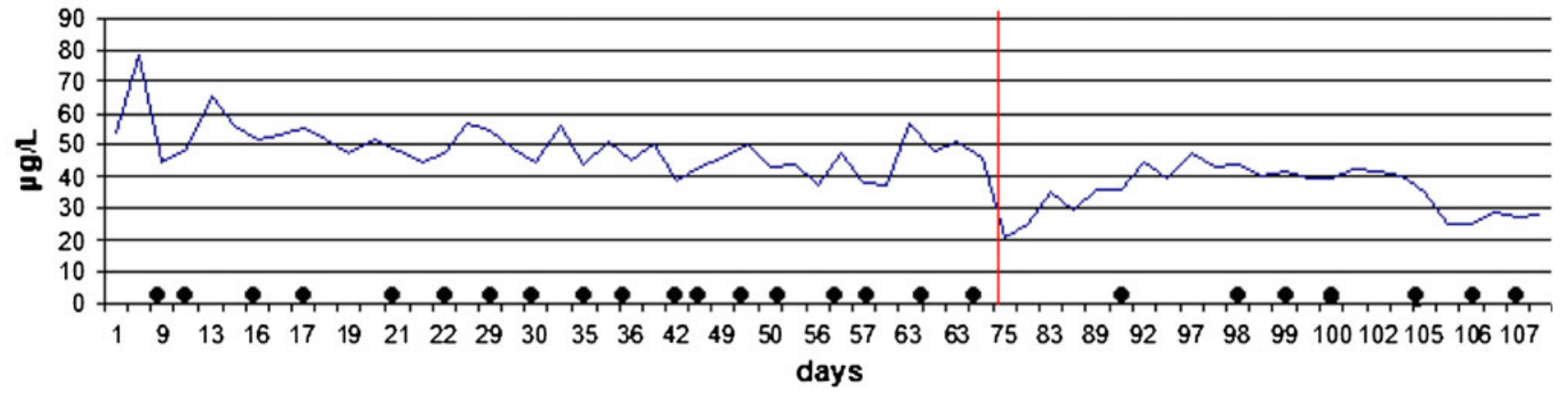

\section{Molybdenum B}

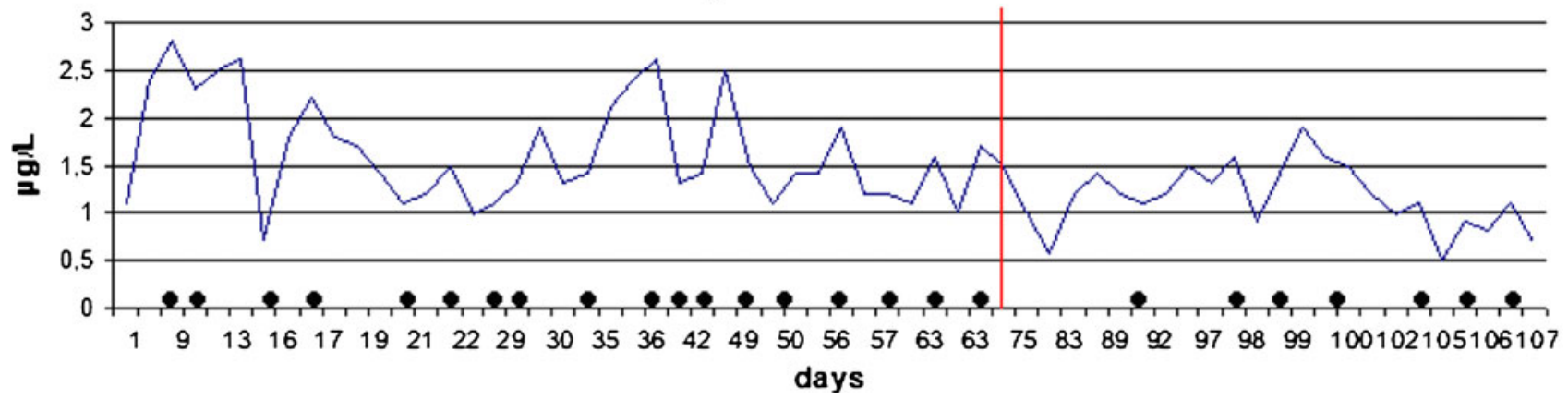

can be explained by the particular situation of a patient with prosthesis subjected to wear. Plasma and other organic fluids are saturated by each of the metal ions released from the active surface according to the solubility curve of each ion [34]; the chelating agent binds and removes part of the soluble ions present in plasma, but further release from the active surface occurs until a new balance is established. The revision of the prosthesis stopped the wear process and also reduced the releasing surface of the disseminated metal debris (washed out by irrigation and by tissue resection during surgery). This produced a significant lowering of cobalt in blood and plasma, however, the effect was less evident on levels of chromium and molybdenum. When tissue deposits of $\mathrm{Cr}$ ions are very high, as occurred in this case, the metal release is slow and it can take several years to de-saturate the tissues. The chelating therapy, moreover, has been proved to be less effective on chromium than on cobalt [25]. After revision there was a rebound effect on the levels of cobalt and chromium, as after an EDTA administration, but without a peak of urinary excretion due to the fact that the soluble ions were removed by open irrigation through the surgical wound. 
Table 2 Plasma, blood and urine levels of cobalt ions from the diagnosis to the end of therapy with EDTA
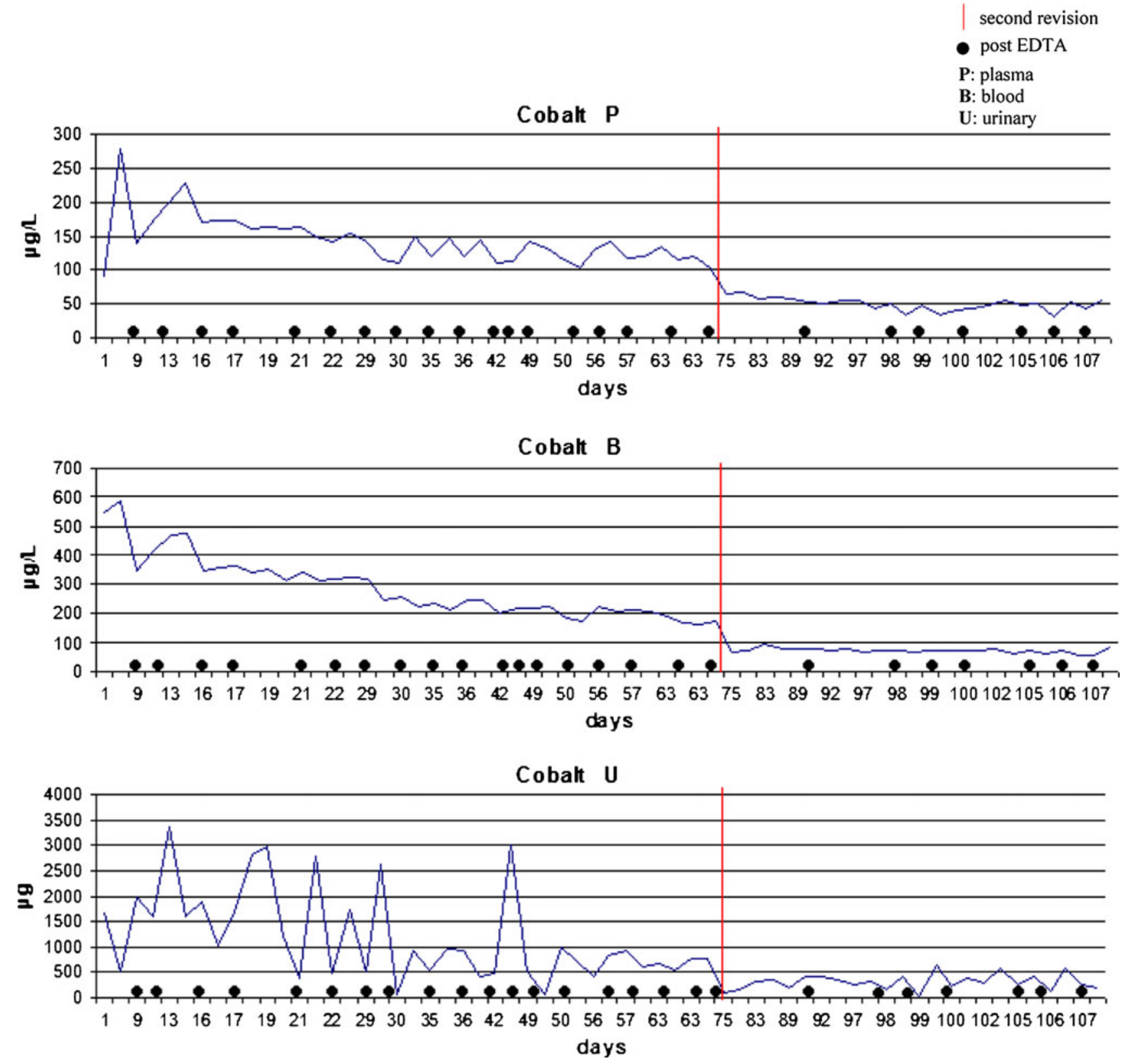

Therefore, the response to revision and to the repeated chelating treatments showed a typical saturation pattern governed by the solubility curves of the ions involved.

Comparing the levels and trends of Co ions in plasma and whole blood during the pre-operative time interval, it was observed that the blood concentration was about double than in plasma and that decrements induced by the chelating treatment were more evident in the latter. This may indicate that a larger fraction of the cobalt released by the implant and the wear particles is bound within the red cells and that the chelating agent removes the more movable plasmatic fraction. After each chelating treatment there was a re-balance, with a passage of ions from the red cell fraction to the serum. In the post-operative period, when the levels of cobalt in blood were reduced to about $1 / 5$ th, the effect was less evident.

The ratio of the individual constituent elements measured in plasma and whole blood in this case did not reflect the Co-Cr-Mo alloy composition (ISO 5832/12). This was not unexpected because corrosion products in aqueous electrolytes can be hydroxides, oxides, soluble salts or occasionally complexes. Therefore, no correlation is 
Table 3 Plasma, blood and urine levels of chromium ions from the diagnosis to the end of therapy with EDTA

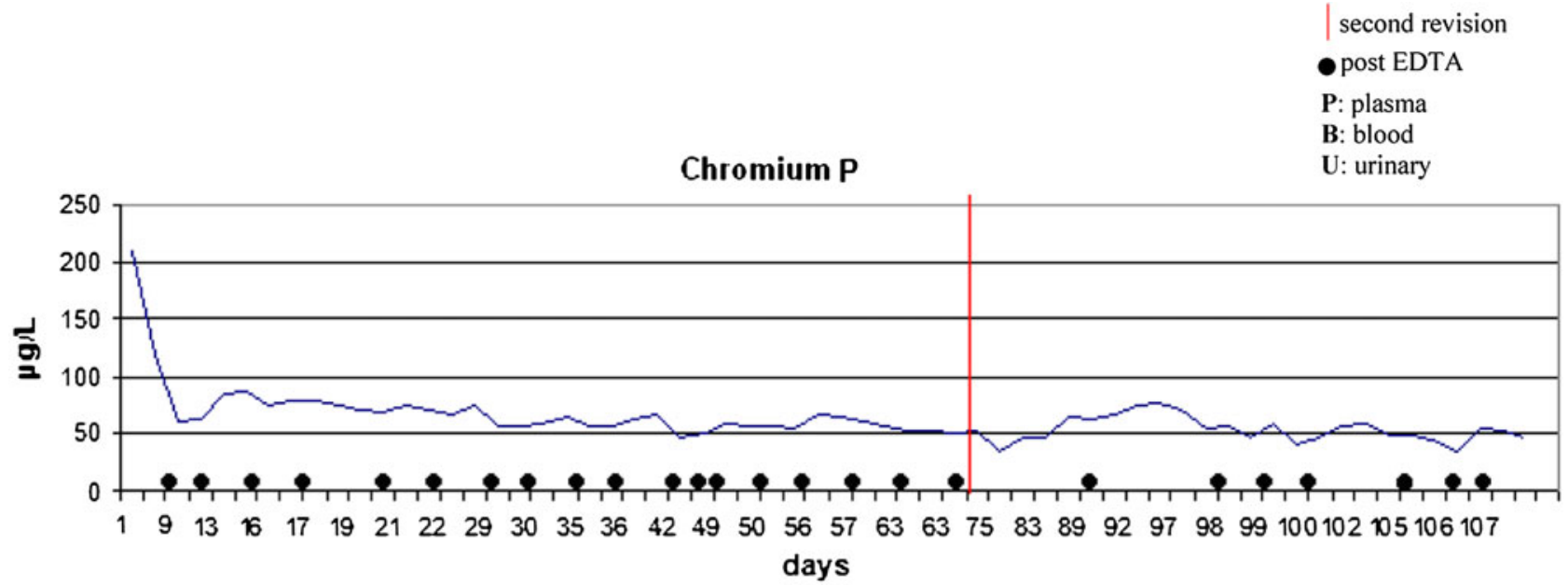

Chromium B

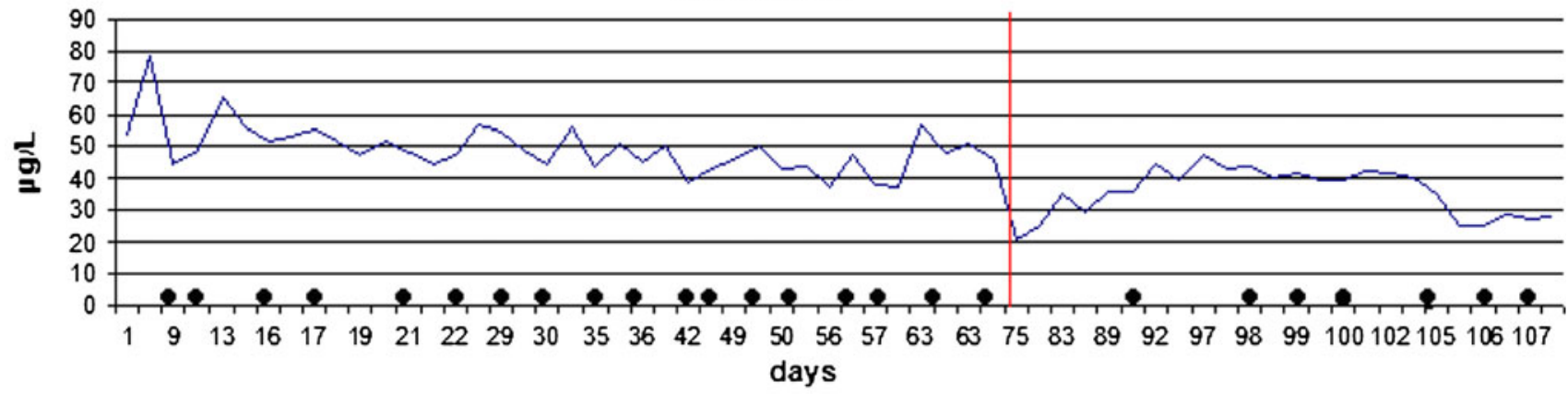

Chromium U

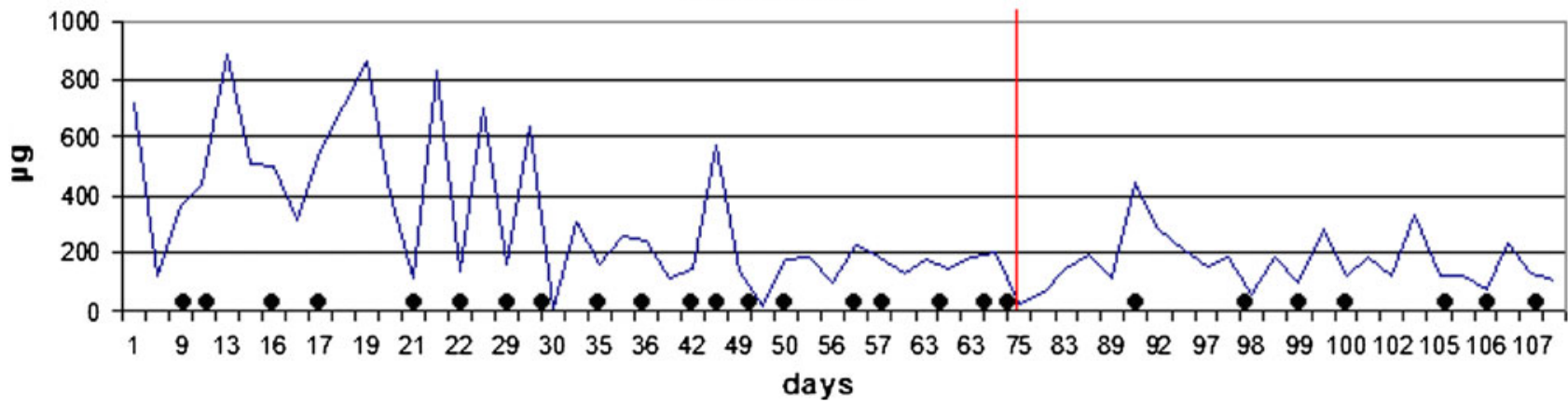

possible between the metal composition of the alloy and the ions levels [34].

Peripheral neuropathies were reported after occupational inhalation exposure to cobalt $[35,36]$; the documented levels of ions in blood were $234 \mu \mathrm{g} / \mathrm{l}$ and the time of exposure corresponded to 20 months, working $50 \mathrm{~h}$ a week. After oral treatment with cobalt chloride maintained for over 2.5 years optic atrophy was observed [37], another case developed with the same treatment for 6 months limbs paraesthesia, unsteady gait, impaired hearing and dusty spells [38]. Our data suggest that high Co ions levels, induced by pathological prosthetic wear, can be a cause of neuropathy and this observation has also been confirmed by two other recent reports $[39,40]$.

Titanium wear particles also originated from the stem and the neck of the prosthesis; however, they were few compared to the mass of $\mathrm{Co}-\mathrm{Cr}-\mathrm{Mo}$ alloy particles.

The concentration of titanium ions was comparable with the reference values [25] and with those of patients with titanium alloy prosthesis with a regular wear rate $[8,37]$. 
After the prosthesis removal, the titanium levels in urine showed a progressive decrement which stabilized at about $10 \mu \mathrm{g} / \mathrm{l}$. Both the analysis of debris and the level of titanium ions did not suggest a role of the latter in the acute intoxication. The ion kinetics documented in this study can be explained by the spreading of the metallic debris by lymphatic or haematogenous route to lymph nodes, spleen, liver and reticulo-endothelial system in general: from these sites the accumulated debris continue to release ions even after the source of wear has been removed.

From the clinical point of view, three suggestions come out:

1. It is preferable not to revise fractured ceramic components with a polyethylene-metal articulation.

2. An early diagnosis of any condition causing excessive wear is a requisite to prevent not only local complications like periprosthetic bone loss, but also a possible systemic intoxication by metal ions [21, 36, $37,39,40]$. In this respect, inductively coupled mass spectrometry determinations of soluble metal ions in biological fluids should be considered as an unavoidable test when suspecting an increased wear rate of the joint prostheses metal components.

3. When massive diffusion of particles through the reticulo-endothelial system has taken place, chelating agents can be considered as an adjuvant therapy to be associated with the implant revision.

Acknowledgments The SEM study of particles was performed with an instrument of Centro Grandi Strumenti University of Insubria, Varese (I). The authors are grateful to Prof. A. Padovani, Dr P. Liberini and Dr M.C. Rizzetti of the Neurology Department of the University of Brescia for referring and allowing to consult the patient's clinical record.

\section{References}

1. Black J (1988) Does corrosion matter? J Bone Jt Surg Br 70(4):517-520

2. Michel R, Nolte M, Reich M, Löer F (1991) Systemic effects of implanted prostheses made of cobalt-chromium alloys. Arch Orthop Trauma Surg 110:61-74

3. Savarino L, Granchi D, Ciapetti G, Stea S, Donati ME, Zinghi G, Fontanesi G, Rotini R, Montanaro L (1999) Effects of metal ions on white blood cells of patients with failed total joint arthroplasties. J Biomed Mater Res 47(4):543-550

4. Visuri T, Pukkala E, Paavalainen P, Pulkkinen P, Riska EB (1996) Cancer risk after metal-on-metal and polyethylene-onmetal total hip arthroplasty. Clin Orthop Relat Res 329S:280-289

5. Clarke MT, Lee PTH, Arora A, Viller RN (2003) Levels of metal ions after small and large diameter metal-on-metal hip arthroplasty. J Bone Jt Surg Br 85-B:913-917

6. Hart AJ, Hester T, Sinclair K, Powell JJ, Goodship AE, Pele L, Fersht NL, Skinner J (2006) The association between metal ions from hip resurfacing and reduced T-cell counts. J Bone Jt Surg Br 88-B(4):449-454

7. Heisel C, Streich N, Krachler M, Jakubowitz E, Kretzer JP (2008) Characterization of the running-in period in total hip resurfacing arthroplasty - an in vivo and in vitro metal ion analysis. J Bone Jt Surg 90(S3):125-133

8. Jacobs JJ, Skipor AK, Patterson LM, Hallab NJ, Paprosky WG, Black J, Galante JO (1998) Metal release in patients who have had a primary total hip arthroplasty. J Bone Jt Surg Am 80-A(10): $1447-1458$

9. Lhotka C, Szekeres T, Steffan I, Zhuber K, Zweymüller K (2003) Four-year study of cobalt and chromium blood levels in patients managed with two different metal-on-metal total hip replacements. J Orthop Res 21(2):189-195

10. Sauvé P, Mountney J, Khan T, De Beer J, Higgins B, Grover M (2007) Metal ion levels after metal-on-metal ring total hop replacement. J Bone Jt Surg Br 89-B:586-590

11. Savarino L, Granchi D, Ciapetti G, Cenni E, Nardi Pantoli A, Rotini R, Veronesi CA, Baldini N, Giunti A (2002) Ion release in patients with metal-on-metal hip bearings in total joint replacement: a comparison with metal-on-polyethylene bearings. J Biomed Mater Res 63:467-474

12. Skipor AK, Campbell PA, Patterson LM, Anstutz HC, Schmalzried TP, Jacobs JJ (2002) Serum and urine metal levels in patients with metal-on-metal surface arthroplasty. J Mater Sci Mater Med 13(12):1227-1234

13. Witzleb WC, Ziegler J, Krummenauer F, Neumeister V, Guenther KP (2006) Exposure to chromium, cobalt and molybdenum from metal-on-metal total hip replacement and hip resurfacing arthroplasty. Acta Orthop 77(5):697-705

14. Kreibich DN, Moran CG, Delves HT, Owen TD, Pinder IM (1996) Systemic release of cobalt and chromium after uncemented total hip replacement. J Bone Jt Surg Br 78-B:18-21

15. Maezawa $K$, Nozawa $M$, Hirose $T$, Matsuda $K$, Yasuma $M$, Shitoto K, Kurosawa H (2002) Cobalt and chromium concentrations in patients with metal-on-metal and other cementless total hip arthroplasty. Arch Orthop Trauma Surg 122:283-287

16. Apostoli $P$ (2002) Elements in environmental and occupational medicine. J Chromatogr B Anal Technol Biomed Life Sci 778(1-2):63-97

17. Scansetti G, Maina G, Botta GC, Bambace P, Spinelli P (1998) Exposure to cobalt and nickel in the hard-metal production industry. Int Arch Occup Environ Health 71(1):60-63

18. Yokota K, Johyama Y, Kunitani Y, Michitsuji H, Yamada S (2007) Urinary elimination of nickel and cobalt in relation to airborne nickel and cobalt exposure in a battery plant. Int Arch Occup Environ Health 80(6):527-531

19. Oldenburg M, Wegner R, Baur X (2009) Severe cobalt intoxication due to prosthesis wear in repeated total hip arthroplasty. J Arthroplasty 24:15-20

20. Rizzetti MC, Liberini P, Zarattini G, Catalani S, Pazzaglia UE, Apostoli P, Padovani A (2009) Loss of sight and sound. Could it be the hip? Lancet 373:1052-1053

21. Steens W, Loehr JF, Von Foerster G, Katzer A (2006) Chronic cobalt poisoning in endoprosthetic replacement. Orthopade 35(8):860-864

22. Case CP, Langkamer VG, James C, Palmer MR, Kemp AJ, Heap PF, Salomon L (1994) Widespread dissemination of metal debris from implants. J Bone Jt Surg Br 76-B:701-712

23. Coleman RF, Herrington J, Scales JT (1973) Concentration of wear products in hair, blood, and urine after total hip replacement. Br Med J 1(5852):527-529

24. Urban RM, Jacobs JJ, Tomlinson MJ, Gavrilovic J, Black J, Peoc'h M (2000) Dissemination of wear particles to the liver, spleen, and abdominal lymph nodes of patients with hip or knee replacement. J Bone Jt Surg Am 82-A:457-477 
25. Nordberg G, Fowler B, Nordberg M, Friberg L (2007) Handbook on the toxicology of metals, 3rd edn. Academic Press, London

26. Krachler M, Heisel C, Kretzer JP (2009) Validation of ultratrace analysis of $\mathrm{Co}, \mathrm{Cr}, \mathrm{Ni}$ and $\mathrm{Mo}$ in whole blood, serum and urine using ICP-SMS. J Anal Atom Spectrom 24:605-610

27. Mears DC (1979) Materials and orthopaedic surgery. Williams and Wilkins Co (ed), Baltimore, pp 107-135

28. Pazzaglia UE, Ceciliani L, Wilkinson MJ, Dell'Orbo C (1985) Involvement of metal particles in loosening of metal-plastic total hip prosthesis. Arch Orthop Trauma Surg 104:164-174

29. Pazzaglia UE, Dell'Orbo C, Wilkinson MJ (1987) The foreign body reaction in total hip arthroplasties. A correlated light microscopy, SEM and TEM study. Arch Orthop Trauma Surg 106:209-219

30. Sodl JF, Bassora R, Huffmann GR, Keenan MA (2008) Traumatic miositis ossificans as a result of collagen fraternity hazing. Clin Orthop Rel Res 466:225-230

31. Kempf I, Semlitsch M (1990) Massive wear of a steel ball head by ceramic fragments in the polyethylene acetabular cup after revision of a total hip prosthesis with fractured ceramic ball. Arch Orthop Trauma Surg 109(5):284-287

32. Kleinhans JA, Jakubowitz E, Seeger JB, Heisel C, Kretzer JP (2009) Macroscopic third-body wear caused by porous metal surface fragments in total hip arthroplasty. Orthopedics 32(5):364
33. Leggett RW (2008) The biokinetics of inorganic cobalt in the human body. Sci Total Environ 389(2-3):259-269

34. Steinemann SG (1994) Corrosion of implant alloys. In: Buchhorn GH, Willert HG (eds) Technical principles. Design and safety of joint implants. Hogrefe and Huber, Seattle, pp 168-179

35. Jordan C, Whitman RD, Harbut M et al (1990) Memory deficits in workers suffering from hand metal disease. Toxicol Lett 54:241-243

36. Meecham HM, Humphrey P (1991) Industrial exposure to cobalt causing optic atrophy and nerve deafness: a case report. J Neural Neurosurg Psychiatry 54(4):374-375

37. Licht A, Oliver M, Rachmilewitz EA (1972) Optic atrophy following treatment with cobalt chloride in a patient with pancytopenia and hypercellular marrow. Isr J Med Sci 8(1):61-66

38. Schirrmacher UO (1967) Case of cobalt poisoning. Br Med J 1(5539):544-545

39. Ikeda T, Takahashi K, Kabata T, Sakagoshi D, Tomita K, Yamada M (2010) Polyneuropathy caused by cobalt-chromium metallosis after total hip replacement. Muscle Nerve 42(1):140-143

40. Tower SS (2010) Cobalt toxicity in two hip replacement patients. Epidemiol Bull 14. http://www.epi.alaska.gov/bulletins/bltndate. jsp. Accessed 28 May 2010 